\title{
Correction to: GC/MS analysis and anti-inflammatory effect of leaf extracts from Hibiscus syriacus through inhibition of NF-KB and MAPKs signaling in LPS-stimulated RAW264.7 macrophages
}

\author{
Hyun Ji Eo ${ }^{1}$ Hae Yun Kwon ${ }^{2}$. Da Som Kim ${ }^{1}$ · Yeongyeong Kang ${ }^{1}$. Youngki Park ${ }^{1}$ Gwang Hun Park ${ }^{1}$ (D)
}

Published online: 25 June 2020

(c) Korean Society for Plant Biotechnology 2020

\section{Correction to: Plant Biotechnology Reports \\ https://doi.org/10.1007/s11816-020-00628-3}

In the original publication of the article, the name of third author was published incorrectly as "Som Da Kim". The correct name is "Da Som Kim".

The original article can be found online at https://doi.org/10.1007/ s11816-020-00628-3.

Gwang Hun Park

ppkh0230@korea.kr

1 Forest Medicinal Resources Research Center, National Institute of Forest Science, Yeongju 36040, Korea

2 Forest Tree Improvement Division, Forest Bioresources Department, National Institute of Forest Science,

Suwon 16631, Korea 